\title{
Low-input Capture-C: A Chromosome Conformation Capture Assay to Analyze Chromatin Architecture in Small Numbers of Cells
}

A. Marieke Oudelaar*, Damien J. Downes, James O.J. Davies and Jim R. Hughes*

Medical Research Council (MRC) Molecular Haematology Unit, Weatherall Institute of Molecular Medicine, University of Oxford, Oxford, United Kingdom

*For correspondence: oudelaar@well.ox.ac.uk; iim.hughes@imm.ox.ac.uk

[Abstract] Chromosome conformation capture (3C) techniques are crucial to understanding tissuespecific regulation of gene expression, but current methods generally require large numbers of cells. This protocol describes two new low-input Capture-C approaches that can generate high-quality $3 \mathrm{C}$ interaction profiles from 10,000-20,000 cells, depending on the resolution used for analysis.

Keywords: Nuclear organization, Chromatin architecture, Chromosome conformation capture (3C), Capture-C, Low input, Small cell numbers

[Background] 3C techniques play a key role in investigating how nuclear organization and structural interactions between regulatory elements relate to gene activity (Dekker et al., 2002). As these interactions are highly tissue-specific, it is crucial that $3 \mathrm{C}$ experiments are performed in well defined, purified cell populations.

A major limitation of $3 C$ techniques is the large numbers of cells required: current methods use between 100,000 and 10 million cells (Davies et al., 2017). Many primary tissues and rare cell populations are not available in these numbers. We have therefore developed two new low-input Capture- $C$ approaches that can generate high-quality interaction profiles from $\sim 20,000$ cells at maximum resolution (individual Dpnll fragments), and from $\sim 10,000$ cells using windowing based analysis (Oudelaar et al., 2017).

\section{Materials and Reagents}

A. 3C library preparation

1. LowBind DNA $1.5 \mathrm{ml}$ microtube

2. Phase Lock Gel (PLG) Light tubes (VWR, Quantabio, catalog number: 733-2477)

3. Genomic DNA ScreenTape (Agilent Technologies, catalog number: 5067-5366)

4. Tapestation Loading Tips (Agilent Technologies, catalog number: 5067-5153)

5. $1 \mathrm{M}$ glycine (Sigma-Aldrich, catalog number: G7126)

6. Phosphate-buffered saline (PBS) (Thermo Fisher Scientific, Gibco ${ }^{\mathrm{TM}}$, catalog number: 10010031)

7. Growth media

8. $37 \%$ formaldehyde (Sigma-Aldrich, catalog number: 252549) 
9. Ethanol absolute $>99.8 \%$ (VWR, catalog number: 20821.330 , or equivalent)

10. Dry ice or liquid nitrogen

11. PCR grade water (Thermo Fisher Scientific, Invitrogen ${ }^{\mathrm{TM}}$, catalog number: AM9932)

12. SDS ( $20 \% \mathrm{v} / \mathrm{v}$ in water) (Thermo Fisher Scientific, Invitrogen ${ }^{\mathrm{TM}}$, catalog number: AM9820)

13. Triton $X-100$ (20\% v/v in water) (Sigma-Aldrich, catalog number: T8787)

14. Dpnll (50,000 U/ml) (New England Biolabs, catalog number: R0543M)

15. T4 DNA ligase $(30 \mathrm{U} / \mu \mathrm{l})$ (Thermo Fisher Scientific, Thermo Scientific ${ }^{\mathrm{TM}}$, catalog number: EL0013)

16. Proteinase K (Thermo Fisher Scientific, Thermo Scientific ${ }^{T M}$, catalog number: EO0491)

17. RNase (DNase-free) (Roche Diagnostics, catalog number: 11119915001)

18. Phenol-chloroform-isoamyl alcohol (PCI) 25:24:1 (Sigma-Aldrich, catalog number: 77617)

19. $3 \mathrm{M}$ NaOAc (Thermo Fisher Scientific, Invitrogen ${ }^{T M}$, catalog number: AM9740)

20. GlycoBlue (Thermo Fisher Scientific, Invitrogen ${ }^{\mathrm{TM}}$, catalog number: AM9515)

21. Genomic DNA Reagents (Agilent Technologies, catalog number: 5067-5365)

22. TaqMan Universal PCR Master Mix II without UNG (Thermo Fisher Scientific, Applied Biosystems ${ }^{\mathrm{TM}}$, catalog number: 4440040)

23. KAPA Sybr Fast Universal (Kapa Biosystems, catalog number: KK4602)

24. Fresh lysis buffer (see Recipes)

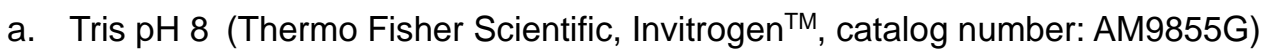
b. Sodium chloride ( $\mathrm{NaCl}$ ) (Thermo Fisher Scientific, Invitrogen ${ }^{\top \mathrm{M}}$, catalog number: AM9760G)
c. Igepal CA-630 (100 $\mu$ l of 10\%) (Sigma-Aldrich, catalog number: I8896)
d. cOmplete Protease Inhibitor Cocktail (1 tablet in $2 \mathrm{ml}$ of PCR grade water for 25x; store at $-20^{\circ} \mathrm{C}$ ) (Sigma-Aldrich, Roche Diagnostics, catalog number: 11873580001)
e. PCR grade water

25. qPCR primers (Appendix I)

B. Addition of Illumina sequencing adaptors by ligation or tagmentation to generate Capture-C libraries

\section{LI-Capture-C}

1. Covaris microTUBE AFA Fiber pre-split snap-cap $6 \times 16 \mathrm{~mm}$ (Covaris, catalog number: 520045)

2. LowBind DNA $1.5 \mathrm{ml}$ microtube

3. PCR tube

4. D1000 ScreenTape (Agilent Technologies, catalog number: 5067-5582)

5. TapeStation Loading Tips (Agilent Technologies, catalog number: 5067-5153)

6. NEBNext Ultra DNA Library Prep Kit for Illumina (New England Biolabs, catalog number: E7370S/L)

7. Agencourt Ampure XP SPRI Beads (Beckman Coulter, catalog number: A63881)

8. NEBNext Multiplex Oligos for Illumina Primer set 1 (New England Biolabs, catalog number: $\mathrm{E} 7335 \mathrm{~S} / \mathrm{L})$ 
9. NEBNext Multiplex Oligos for Illumina Primer set 2 (New England Biolabs, catalog number: E7500S/L)

10. Herculase II Fusion Polymerase Kit (Agilent Technologies, catalog number: 600677)

11. PCR grade water (Thermo Fisher Scientific, Invitrogen ${ }^{\mathrm{TM}}$, catalog number: AM9932)

12. Ethanol absolute $>99.8 \%$ (VWR, catalog number: 20821.330 , or equivalent)

13. D1000 Reagents (Agilent Technologies, catalog number: 5067-5583)

14. Qubit dsDNA BR Assay kit (Thermo Fisher Scientific, Invitrogen ${ }^{\mathrm{TM}}$, catalog number: Q32850)

\section{Tag-Capture-C}

1. LowBind DNA $1.5 \mathrm{ml}$ microtube

2. PCR tube

3. High Sensitivity D1000 ScreenTape (Agilent Technologies, catalog number: 5067-5584)

4. D1000 ScreenTape (Agilent Technologies, catalog number: 5067-5582)

5. TapeStation Loading Tips (Agilent Technologies, catalog number: 5067-5153)

6. Nextera DNA Sample Preparation Kit (Illumina, catalog number: FC-121-1030/1031)

7. Zymo DNA Clean \& Concentrator-5 Kit (Zymo Research, catalog number: D4013)

8. KAPA HiFi PCR Kit with dNTP (KK2102) (Roche Diagnostics, catalog number: 07958846001)

9. Custom designed index primers

10. Agencourt Ampure XP SPRI Beads (Beckman Coulter, catalog number: A63881)

11. PCR grade water (Thermo Fisher Scientific, Invitrogen ${ }^{\mathrm{TM}}$, catalog number: AM9932)

12. Ethanol absolute $>99.8 \%$ (VWR, catalog number: 20821.330 , or equivalent)

13. High Sensitivity D1000 Reagents (Agilent Technologies, catalog number: 5067-5585)

14. D1000 Reagents (Agilent Technologies, catalog number: 5067-5583)

15. Qubit dsDNA BR Assay kit (Thermo Fisher Scientific, Invitrogen ${ }^{\mathrm{TM}}$, catalog number: Q32850)

C. Enrichment for viewpoints of interest by oligonucleotide capture

1. Safeseal Microcentrifuge Tubes (Sorenson BioScience, catalog number: 39640T)

2. D1000 ScreenTape (Agilent Technologies, catalog number: 5067-5582)

3. Tapestation Loading Tips (Agilent Technologies, catalog number: 5067-5153)

4. Nimblegen SeqCap EZ Hybridization and wash kit (Roche Diagnostics, catalog number: 05634261001)

5. Nimblegen SeqCap EZ Accessory kit v2 (Roche Diagnostics, catalog number: 07145594001)

6. $1 \mu \mathrm{g} / \mu \mathrm{l}$ COT DNA of relevant species (Mouse) (Thermo Fisher Scientific, Invitrogen ${ }^{\mathrm{TM}}$, catalog number: 18440016)

7. M-270 Streptavidin Dynabeads (Thermo Fisher Scientific, Invitrogen ${ }^{\mathrm{TM}}$, catalog number: 65305 )

8. Agencourt Ampure XP SPRI Beads (Beckman Coulter, catalog number: A63881)

9. PCR grade water (Thermo Fisher Scientific, Invitrogen ${ }^{\mathrm{TM}}$, catalog number: AM9932)

10. Qubit dsDNA BR Assay Kit (Thermo Fisher Scientific, Invitrogen ${ }^{\mathrm{TM}}$, catalog number: Q32850)

11. Qubit dsDNA HS Assay Kit (Thermo Fisher Scientific, Invitrogen ${ }^{\mathrm{TM}}$, catalog number: Q32851) 
12. D1000 Reagents (Agilent Technologies, catalog number: 5067-5583)

13. KAPA Library Quantification Complete Kit (Universal) (Kapa Biosystems, catalog number: KK4824)

14. LI-Capture-C

Nimblegen SeqCap EZ HE-oligo kit A (Roche Diagnostics, catalog number: 06777287001)

Nimblegen SeqCap EZ HE-oligo kit B (Roche Diagnostics, catalog number: 06777317001)

15. Tag-Capture-C

xGen Custom Blocking Oligos (P5/i5 \& P7/i7 Nextera blocker)

\section{Equipment}

1. Centrifuge

2. Incubator (any)

3. Eppendorf Thermomixer C (or equivalent shaking incubator) (Eppendorf, model: ThermoMixer ${ }^{\circledR} \mathrm{C}$, catalog number: 5382000015)

4. P10, P20, P200 and P1000 pipettes (any)

5. Thermocycler (any)

6. NanoDrop

7. Agilent 2200 TapeStation (Agilent Technologies, model: Agilent 2200 TapeStation System) Note: Assessments on the Agilent TapeStation can also be performed on the Agilent BioAnalyzer.

8. Sonicator (Covaris, model: S220 Focused-ultrasonicator)

9. DynaMag-2 (Thermo Fisher Scientific, catalog number: 12321D)

10. Vacuum Concentrator (SciQuip, CHRIST series) 


\section{Procedure}

\section{Overview}

Note: Overview of the procedure (Graphics adapted from Davies et al., 2017).

A. 3 C library preparation (5 days)

1. Fixation-2 $\mathrm{h}$

2. Digestion-1 $d$

3. Ligation-1 d

4. De-crosslinking-1 d

5. DNA extraction-1 d

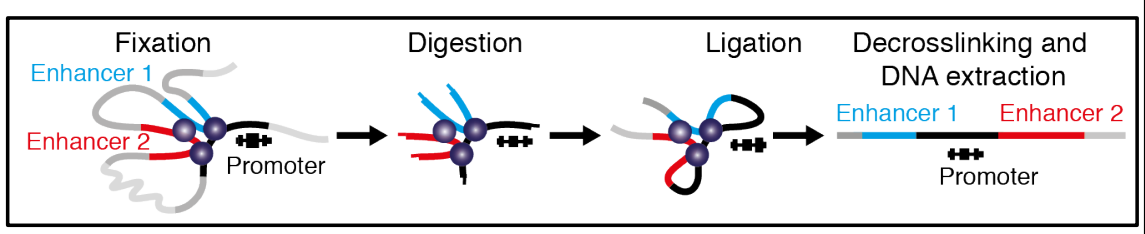

6. Quantification and QC-3 h

B. Addition of Illumina sequencing adaptors by ligation or tagmentation to generate Capture-C libraries (2 days)

LI-Capture-C:

1. Sonication-1/2 d

2. End repair and adaptor ligation-1/2 $\mathrm{d}$

3. PCR addition of indices- $-1 / 2 \mathrm{~d}$

Or

Tag-Capture-C:

1. Tagmentation-1 d

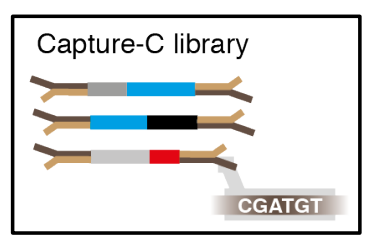

2. PCR addition of indices- $-1 / 2 \mathrm{~d}$

C. Enrichment for viewpoints of interest by oligonucleotide capture (8 days)

1. Capture I
a. Hybridization-4 d
b. Washing and recovery of captured material-1 d
C. PCR amplification of captured material-1 d

2. Capture II
a. Hybridization-1 d
b. Washing and recovery of captured material-1/2 $d$
c. PCR amplification of captured material-1/2 $d$

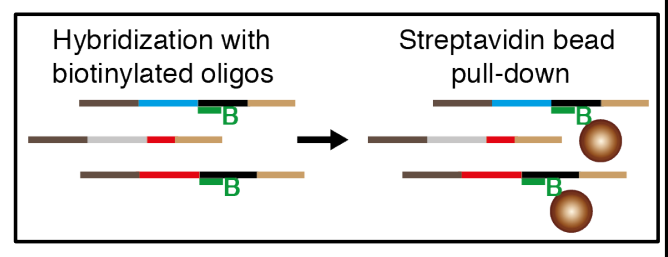




\section{Steps}

A. $3 \mathrm{C}$ library preparation

1. Fixation (2 h)

Note: The fixation procedure described below has been optimized for erythroid cells. Depending on the cell type used, some of centrifugation steps might need to be adjusted to ensure proper pelleting.

a. Pre-cool centrifuge to $4^{\circ} \mathrm{C}$. Chill glycine, PBS, and lysis buffer (see Recipes).

b. Collect cells from tissue and make single-cell suspensions of 10,000 to $10^{6}$ cells in $1 \mathrm{ml}$ growth media. If sorting cells, sort into $100 \mu \mathrm{l}$ media and add media afterwards to a total volume of $1 \mathrm{ml}$.

c. Add $54 \mu \mathrm{l} 37 \%$ formaldehyde ( $2 \%$ final concentration), mix well and incubate for $10 \mathrm{~min}$ at $\mathrm{RT}$ on a rocking or tumbling incubator.

d. Quench by adding $150 \mu \mathrm{l} 1 \mathrm{M}$ cold glycine (1/8 of the final volume. i.e., $1.2 \mathrm{ml}$ ).

e. Centrifuge for $15 \mathrm{~min} / 500 \times \mathrm{g} / 4^{\circ} \mathrm{C}$.

f. Carefully remove supernatant, do not disturb pellet. Can leave $\sim 5 \%$ behind.

g. Wash pellet by gently resuspending in $1 \mathrm{ml}$ cold PBS.

h. Centrifuge for $15 \mathrm{~min} / 500 \times \mathrm{g} / 4^{\circ} \mathrm{C}$.

i. Carefully remove supernatant, do not disturb pellet. Can leave $\sim 5 \%$ behind.

j. Resuspend pellet in $500 \mu \mathrm{l}$ cold lysis buffer.

k. Incubate for $20 \mathrm{~min}$ on ice.

I. Snap freeze with ethanol and dry ice or liquid nitrogen. Snap freezing aids digestion so cells can be thawed again for digestion at this point or stored long-term at $-80^{\circ} \mathrm{C}$.

SAFE STOPPING POINT: Store at $-80^{\circ} \mathrm{C}$.

2. Digestion (1 day)

a. Pre-warm a ThermoMixer to $37^{\circ} \mathrm{C}$.

b. Prepare Digestion Mix (make a master mix for multiple libraries):

PCR grade water $\quad 152.5 \mu \mathrm{l}$

10x Dpnll Buffer $\quad 20 \mu \mathrm{l}$

$20 \%$ SDS $\quad 2.5 \mu \mathrm{l}$

c. Defrost aliquots of 10,000 to $10^{6}$ formaldehyde-fixed cells for each reaction.

d. Centrifuge for $10 \mathrm{~min} / 15,000 \times \mathrm{g} / 4{ }^{\circ} \mathrm{C}$.

e. Carefully remove all the lysis buffer, using a P20 to remove residual buffer without disturbing the pellet.

f. Resuspend in $175 \mu$ l of Digestion Mix.

g. Shake horizontally $(1,400 \mathrm{rpm})$ for $1 \mathrm{~h}$ at $37^{\circ} \mathrm{C}$ using the ThermoMixer.

h. Add $16 \mu \mathrm{l}$ of $20 \%$ Triton X-100 (1.7\% final concentration) and shake for $1 \mathrm{~h}$ at $37^{\circ} \mathrm{C}$.

i. Add first aliquot of $3 \mu \mathrm{l}$ of $D p n l l$ enzyme and shake at $37^{\circ} \mathrm{C}$ for at least two hours.

j. Add a second aliquot of $3 \mu \mathrm{l}$ of Dpnll enzyme at the end of the day and shake overnight.

k. Add a further $3 \mu$ l of $D p n l l$ enzyme the next morning and shake for at least three more hours. 
3. Ligation (1 day)

a. Place the digests on the $65{ }^{\circ} \mathrm{C}$ block for 20 min to heat inactivate the restriction enzyme.

b. Cool the digest on ice and cool the ThermoMixer to $16{ }^{\circ} \mathrm{C}$.

c. Make Ligation Mix (make a master mix for multiple libraries):

PCR grade water $\quad 125 \mu \mathrm{l}$

10x ligation buffer $\quad 36 \mu \mathrm{l}$

d. Add $161 \mu \mathrm{l}$ Ligation Mix to digest.

e. Add $4 \mu \mathrm{l} \mathrm{T} 4$ ligase and shake at $300 \mathrm{rpm} / 16^{\circ} \mathrm{C}$ for $\sim 22 \mathrm{~h}$.

4. De-crosslinking (1 day)

Add $2 \mu \mathrm{l}$ Proteinase $\mathrm{K}(20 \mathrm{mg} / \mathrm{ml})$ and incubate at $65^{\circ} \mathrm{C}$ overnight.

5. DNA extraction (1 day)

a. Add $4 \mu \mathrm{l}$ of RNase to the ligation reaction and incubate at $37^{\circ} \mathrm{C}$ for $30 \mathrm{~min}$.

b. Add $350 \mu$ l phenol-chloroform-isoamyl alcohol and vortex thoroughly.

c. Transfer to a $2 \mathrm{ml} \mathrm{PLG} \mathrm{Light} \mathrm{tube} \mathrm{and} \mathrm{spin} \mathrm{for} 5 \mathrm{~min} / 15,000 \times \mathrm{g} / \mathrm{RT}$.

d. Transfer the upper layer, $\sim 350 \mu$ l, to a new tube.

e. Add $35 \mu \mathrm{l}$ of $3 \mathrm{M} \mathrm{NaOAc}$ and $2 \mu \mathrm{l}$ of GlycoBlue and mix by inversion.

f. Add $960 \mu \mathrm{l}$ of $100 \%$ ethanol and mix by inversion.

g. Freeze at $-20^{\circ} \mathrm{C}$ overnight.

SAFE STOPPING POINT: DNA should be precipitated for at least one night; this can be extended to several days without affecting recovery.

h. Pre-cool centrifuge to $4{ }^{\circ} \mathrm{C}$ during incubation.

i. Centrifuge for $45 \mathrm{~min} / 21,000 \times \mathrm{g} / 4^{\circ} \mathrm{C}$ and carefully discard liquid.

j. Wash pellet with $1 \mathrm{ml} 70 \%$ ice-cold ethanol.

k. Spin for $10 \mathrm{~min} / 21,000 \times \mathrm{g} / 4^{\circ} \mathrm{C}$.

I. Remove ethanol and repeat ethanol wash (steps A5j-A5k).

$\mathrm{m}$. Remove ethanol, spin in a microfuge and use a pipette to remove residual ethanol.

Dry at room temperature and resuspend pellet. When proceeding with LI-Capture-C, resuspend in $124 \mu \mathrm{l}$ water. For Tag-Capture-C, the amount of water depends on the input, as several tagmentation reactions are set up in parallel (explained below). Use $20 \mu \mathrm{l}$ water per multitude of 15,000 cells and round up (e.g., 30,000 cells:40 $\mu \mathrm{l}$ water; 50,000 cells:80 $\mu$ water).

SAFE STOPPING POINT: Store at $-20^{\circ} \mathrm{C}$.

6. Quantification and QC (3 h)

Note: The NanoDrop or similar spectrophotometers are unreliable for quantifying $3 C$ libraries due to residual DTT from the ligation buffer.

a. Assess $1 \mu \mathrm{l}$ of $3 \mathrm{C}$ library using the Agilent Genomic ScreenTape system to determine the size distribution of library (Appendix I).

b. For LI-Capture-C-take $3 \mu \mathrm{l}$ of $3 \mathrm{C}$ library and $27 \mu \mathrm{l}$ water to make a 1/10 dilution; for TagCapture-C-take $1 \mu \mathrm{l}$ of $3 \mathrm{C}$ library and $29 \mu \mathrm{l}$ water to make a 1/30 dilution. 
Perform qPCR for digestion efficiency, using the dilution. Genomic DNA can be used as the undigested control (Appendix I). Digestion efficiency should be $>75 \%$.

B. Addition of Illumina sequencing adaptors by ligation or tagmentation to generate Capture-C libraries

\section{LI-Capture-C}

-Based on the protocol for the NEBNext Ultra DNA Library Prep Kit for Illumina (E7370)

Notes:

a. In this step, it is important to maintain library complexity by maximizing input DNA and minimizing DNA losses during the reactions and cleanups. When more than $1 \mu \mathrm{g}$ of DNA is available, perform parallel preparations. These can be pooled during cleanups and at the end.

$b$. The NEB protocol often recommends removing the DNA from the beads with a few $\mu$ l more water than is necessary for the next step in the protocol. One can avoid doing this to minimize losses, but this means being very careful with the bead cleanups as contamination by the beads or ethanol can inhibit the following reaction.

c. We use the Covaris S220 Focused Ultrasonicator for sonication. If using a different model sonicator, use high molecular weight gDNA to optimize sonication for a modal distribution around 200 bp in size (Appendix II).

d. The Illumina indices that you put on to the library need to be complementary to the Nimblegen HE blocking oligonucleotides required in the capture step (the kits do not match; Appendix II). Buying both primer set 1 and primer set 2 eliminates waste of the more expensive Nimblegen blocking kit.

e. No size selection is necessary as adaptor dimers will not be captured. All Ampure XP bead cleanups are performed with $1.8 x$ volumes of beads.

1. Sonication (1 h)

a. Take $120 \mu \mathrm{l}$ of $3 \mathrm{C}$ library (up to $1 \mu \mathrm{g}$ ) and transfer to a Covaris microtube. Avoid making bubbles.

b. Shear DNA to $200 \mathrm{bp}$ with the following settings:

Duty cycle: $10 \%$

Intensity: 5

Cycles per burst: 200

Time: $360 \mathrm{sec}$

Set mode: Frequency sweeping

c. Ampure XP SPRI bead cleanup:

i. Transfer reaction from the Covaris microtube to a lowBind DNA $1.5 \mathrm{ml}$ microtube.

ii. Add $220 \mu$ l beads, pipette up and down 10 times, allow to bind at RT for $5 \mathrm{~min}$.

iii. Place on the DynaMag, discard liquid when clear. 
iv. Add $500 \mu \mathrm{l}$ of fresh $80 \%$ ethanol without removing from the DynaMag. Avoid disturbing beads by running the ethanol down the front of the tube. Allow to sit on the rack for 30 sec at RT, then remove ethanol.

v. Remove ethanol and add another $500 \mu \mathrm{l}$ of fresh $80 \%$ ethanol, allow to sit for $30 \mathrm{sec}$ at $\mathrm{RT}$ and remove all the ethanol.

vi. $\quad$ Spin down on microfuge and remove residual ethanol with a P10 pipette.

vii. Air dry at room temperature on the DynaMag until matt in appearance.

Note: Be careful not to over dry the beads as this will result in increased DNA losses.

viii. Resuspend beads in $56 \mu$ l water to elute DNA, mix by pipetting 10 times.

ix. Incubate at RT for 2 min.

x. Recover $55.5 \mu \mathrm{l}$ for End Repair reaction.

d. Optional: Assess $1 \mu \mathrm{l}$ of sonicated material using the Agilent D1000 (Regular or High Sensitivity, depending on your input) ScreenTape system (Appendix II).

SAFE STOPPING POINT: Store at $-20^{\circ} \mathrm{C}$.

2. End repair and adaptor ligation $(2 \mathrm{~h})$

a. Combine $55.5 \mu \mathrm{l}$ of DNA ( $5 \mathrm{ng}-1 \mu \mathrm{g}), 6.5 \mu \mathrm{l}$ 10x End Repair Reaction Buffer (Green) and 3 $\mu \mathrm{l}$ End Prep Enzyme Mix (Green). Mix by pipetting and briefly spin down.

b. Incubate in a thermocycler:

$20^{\circ} \mathrm{C}$ for $30 \mathrm{~min}$

$65^{\circ} \mathrm{C}$ for $30 \mathrm{~min}$

c. Add $15 \mu \mathrm{l}$ Blunt/TA Ligase Master Mix (Red), $2.5 \mu \mathrm{l}$ NEBNext Adaptor* (Red), $1 \mu \mathrm{l}$ Ligation Enhancer (Red). Mix by pipetting and briefly spin down.

*Note: If DNA input is < $100 \mathrm{ng}$, dilute the NEBNext Adaptor for Illumina (provided at $15 \mu \mathrm{M}$ ) 10-fold in $10 \mathrm{mM}$ Tris- $\mathrm{HCl}$ or $10 \mathrm{mM}$ Tris- $\mathrm{HCl}$ with $10 \mathrm{mM} \mathrm{NaCl}$ to a final concentration of $1.5 \mu \mathrm{M}$, use immediately.

d. Incubate for $15 \mathrm{~min}$ at $20^{\circ} \mathrm{C}$ in a thermocycler.

e. Add $3 \mu$ l of USER Enzyme (Red). Mix by pipetting.

f. Incubate for $15 \mathrm{~min}$ at $37^{\circ} \mathrm{C}$ in a thermocycler.

g. Ampure XP SPRI bead cleanup:

i. Transfer reaction to a lowBind DNA $1.5 \mathrm{ml}$ microtube.

ii. Add $160 \mu$ l beads, pipette up and down 10 times, allow to bind at RT for $5 \mathrm{~min}$.

iii. Place on the DynaMag, discard liquid when clear.

iv. Add $500 \mu \mathrm{l}$ of fresh $80 \%$ ethanol without removing from the DynaMag. Avoid disturbing beads by running the ethanol down the front of the tube. Allow to sit on the rack for 30 sec at RT, then remove ethanol.

v. Remove ethanol and add another $500 \mu \mathrm{l}$ of fresh $80 \%$ ethanol, allow to sit for $30 \mathrm{sec}$ at RT and remove all the ethanol.

vi. Spin down in a microfuge and remove residual ethanol with a P10 pipette.

vii. Air dry at room temperature on the DynaMag until matt in appearance. 
Note: Be careful not to over dry the beads as this will result in increased DNA losses.

viii. Resuspend beads in $29 \mu$ l water, mix by pipetting 10 times.

ix. Incubate at RT for $2 \mathrm{~min}$.

X. Transfer $28.5 \mu$ l eluted DNA to a PCR tube.

3. PCR addition of indices ( $2 \mathrm{~h})$

Note: Carefully choose your index to allow for multiplexing using the Illumina pooling guidelines.

a. Perform PCR as described below.

\begin{tabular}{|l|l|}
\hline Adaptor ligated 3C library & $28.5 \mu \mathrm{l}$ \\
\hline NEB Universal primer & $5 \mu \mathrm{l}$ \\
\hline NEB Index primer & $5 \mu \mathrm{l}$ \\
\hline Herculase II Reaction Buffer (5x) & $10 \mu \mathrm{l}$ \\
\hline dNTP Mix (25 mM) & $0.5 \mu \mathrm{l}$ \\
\hline Herculase II Fusion DNA Polymerase & $1 \mu \mathrm{l}$ \\
\hline & Total $50 \mu \mathrm{l}$ \\
\hline
\end{tabular}

\begin{tabular}{|l|l|l|}
\hline Step 1 & $98^{\circ} \mathrm{C}$ & $30 \mathrm{sec}$ \\
\hline Step 2 & $98^{\circ} \mathrm{C}$ & $10 \mathrm{sec}$ \\
\hline Step 3 & $65^{\circ} \mathrm{C}$ & $30 \mathrm{sec}$ \\
\hline Step 4 & $72^{\circ} \mathrm{C}$ & $30 \mathrm{sec}$ \\
\hline Step 5 & Go to Step 2 & 9 cycles \\
\hline Step 6 & $72^{\circ} \mathrm{C}$ & $5 \mathrm{~min}$ \\
\hline Step 7 & $4^{\circ} \mathrm{C}$ & Hold \\
\hline
\end{tabular}

b. Ampure XP SPRI bead cleanup:

i. Transfer reaction to a lowBind DNA $1.5 \mathrm{ml}$ microtube.

ii. $\quad$ Add $90 \mu$ l beads, pipette up and down 10 times, allow to bind at RT for 5 min.

iii. Place on the DynaMag, discard liquid when clear.

iv. Add $500 \mu \mathrm{l}$ of fresh $80 \%$ ethanol without removing from the DynaMag. Avoid disturbing beads by running the ethanol down the front of the tube. Allow to sit on the rack for 30 sec at RT, then remove ethanol.

v. Remove ethanol and add another $500 \mu$ of fresh $80 \%$ ethanol, allow to sit for 30 sec at RT and remove all the ethanol.

vi. Spin down in a microfuge and remove residual ethanol with a P10 pipette.

vii. Air dry at room temperature on the DynaMag until matt in appearance.

Note: Be careful not to over dry the beads as this will result in increased DNA losses.

viii. Resuspend beads in $31 \mu$ water, mix by pipetting 10 times.

ix. Incubate at RT for $2 \mathrm{~min}$.

X. Recover $30 \mu \mathrm{l}$.

C. Assess $1 \mu \mathrm{l}$ of material using the Agilent D1000 ScreenTape system (Appendix II page 3).

d. Quantify library using Qubit dsDNA BR assay kit.

SAFE STOPPING POINT: Store at $-20{ }^{\circ} \mathrm{C}$.

\section{Tag-Capture-C}

Notes:

a. In this step, it is important to maintain library complexity by maximizing input DNA and minimizing DNA losses during the reactions and cleanups. The maximum input for a tagmentation reaction is $50 \mathrm{ng}$. When input is higher, run several separate reactions in parallel; these can be pooled after the cleanup. 
b. We use custom designed index primers, for which the sequences can be found in the Appendix. We order these as TruGrade Primers from IDT.

c. No size selection is necessary as adaptor dimers won't be captured. All Ampure XP bead cleanups are performed with $1.8 x$ volumes of beads.

1. Tagmentation (1 day)

a. Prepare tagmentation reactions with reagents from the Nextera DNA Sample Preparation Kit in a PCR tube:

$<50$ ng 3 C library in $20 \mu$ water

$25 \mu \mathrm{l}$ TD Buffer

$5 \mu \mathrm{l}$ of TD Enzyme

b. Mix by pipetting, followed by a quick spin.

c. Incubate at $55^{\circ} \mathrm{C}$ for $12-24 \mathrm{~h}$ to ensure all material is tagmented.

d. Zymo spin column cleanup:

i. Label tubes and add $180 \mu \mathrm{l}$ of Zymo DNA Binding Buffer.

ii. Add $50 \mu$ l of tagmented DNA. Gently pipette up and down 10 times to mix.

iii. Transfer sample mixture to a Zymo spin column in a collection tube.

iv. Centrifuge for $30 \mathrm{sec}$ at 15,000 $\mathrm{xg}$. Discard the flow-through.

v. Add $200 \mu \mathrm{l}$ Zymo DNA Wash Buffer to the column. Centrifuge for $30 \mathrm{sec}$ at 15,000 $\mathrm{xg}$.

vi. Repeat step B1d.v (Tag-Capture-C section) and centrifuge in addition $60 \mathrm{sec}$ at 15,000 $x g$.

vii. Transfer the column to a $1.5 \mathrm{ml}$ tube and add $34.5 \mu \mathrm{l}$ of water to the column matrix. Incubate at RT for 2 min.

viii. Centrifuge for $1 \mathrm{~min}$ at $15,000 \times g$ to elute the DNA.

e. Assess $1 \mu \mathrm{l}$ of material using the Agilent High Sensitivity D1000 ScreenTape system (Appendix III).

2. $\mathrm{PCR}$ addition of indices $(2 \mathrm{~h})$

Note: Carefully choose your index to allow for multiplexing using the Illumina pooling guidelines.

a. Perform PCR as described below.

\begin{tabular}{|l|l|}
\hline Tagmented 3C library & $33.5 \mu \mathrm{l}$ \\
\hline Universal primer $(25 \mu \mathrm{M})$ & $2 \mu \mathrm{l}$ \\
\hline Index primer $(25 \mu \mathrm{M})$ & $2 \mu \mathrm{l}$ \\
\hline KAPA HiFi Fidelity Buffer $(5 \mathrm{x})$ & $10 \mu \mathrm{l}$ \\
\hline KAPA dNTP Mix $(10 \mathrm{mM})$ & $1.5 \mu \mathrm{l}$ \\
\hline KAPA HiFi DNA Polymerase $(1 \mathrm{U} / \mu \mathrm{l})$ & $1 \mu \mathrm{l}$ \\
\hline & Total $50 \mu \mathrm{l}$ \\
\hline
\end{tabular}

\begin{tabular}{|l|l|l|}
\hline Step 1 & $72^{\circ} \mathrm{C}$ & $5 \mathrm{~min}$ \\
\hline Step 2 & $98^{\circ} \mathrm{C}$ & $30 \mathrm{seC}$ \\
\hline Step 3 & $98^{\circ} \mathrm{C}$ & $10 \mathrm{sec}$ \\
\hline Step 4 & $63^{\circ} \mathrm{C}$ & $30 \mathrm{sec}$ \\
\hline Step 5 & $72^{\circ} \mathrm{C}$ & $1 \mathrm{~min}$ \\
\hline Step 6 & Go to Step 3 & 9 cycles \\
\hline Step 7 & $72{ }^{\circ} \mathrm{C}$ & $3 \mathrm{~min}$ \\
\hline Step 8 & $4^{\circ} \mathrm{C}$ & Hold \\
\hline
\end{tabular}

b. Ampure XP SPRI bead cleanup:

i. Transfer reaction to a lowBind DNA $1.5 \mathrm{ml}$ microtube.

ii. Add $90 \mu \mathrm{l}$ beads, pipette up and down 10 times, allow to bind at RT for 5 min. 
iii. Place on the DynaMag, discard liquid when clear.

iv. Add $500 \mu \mathrm{l}$ of fresh $80 \%$ ethanol without removing from the DynaMag. Avoid disturbing beads by running the ethanol down the front of the tube. Allow to sit on the rack for 30 sec at RT, then remove ethanol.

v. Remove ethanol and add another $500 \mu \mathrm{l}$ of fresh $80 \%$ ethanol, allow to sit for $30 \mathrm{sec}$ at $\mathrm{RT}$ and remove all the ethanol.

vi. Spin down in a microfuge and remove residual ethanol with a P10 pipette.

vii. Air dry at room temperature on the DynaMag until matt in appearance.

Note: Be careful not to over dry the beads as this will result in increased DNA losses.

viii. Resuspend beads in $31 \mu$ water, mix by pipetting 10 times.

ix. Incubate at RT for 2 min.

X. Recover $30 \mu \mathrm{l}$.

c. Assess $1 \mu \mathrm{l}$ of material using the Agilent D1000 ScreenTape system (Appendix III page 4).

d. Quantify library using Qubit dsDNA BR assay kit.

SAFE STOPPING POINT: Store at $-20^{\circ} \mathrm{C}$.

C. Enrichment for viewpoints of interest by oligonucleotide capture

-Based on the Nimblegen SeqCap SR User's Guide Chapter 5-7

Note: The blocking oligonucleotides must be complementary to the adapters in your library. If performing LI-Capture-C, you can use the commercially available blocking oligonucleotides from Nimblegen. If you are following the Tag-Capture-C protocol, you can contact IDT and design blocking oligonucleotides using their xGen Custom Blocking Oligos service. We used a universal blocker for both the i5 adapter and i7 adapters, so we only needed 2 blocking oligonucleotides for all possible index combinations.

1. Hybridization preparation (1 day)

Note: Ensure capture oligonucleotides for different experiments are kept apart. The oligonucleotides are hugely in excess and tiny amounts of contamination can lead to spurious results. We would recommend that you do not order oligonucleotides that should not be mixed from the manufacturer at the same time. Avoid having buffers and blocking oligonucleotides out at the same time as the capture oligonucleotides. Oligonucleotides that are going to be pooled for a single experiment, can be ordered together. Consider ordering large designs in as a pooled set (at equimolar concentrations).

\section{Biotinylated capture oligonucleotides}

a. Reconstitute individual or pools of oligonucleotides to a stock concentration so that each oligo is stored at $2.9 \mu \mathrm{M}$ (10 nmol in $3.46 \mu \mathrm{l}$ of PCR grade water)-or any high concentration.

b. Generate pools of oligonucleotides by mixing in exact 1:1 stoichiometric ratio.

\section{Nimblegen blocking oligonucleotides (LI-Capture-C)}

Resuspend Nimblegen oligonucleotides according to the Nimblegen protocol:

a. Spin down tubes in a minifuge. 
b. Add $120 \mu \mathrm{l} \mathrm{PCR}$ grade water to the HE Universal Oligo tube (1 mM); vortex and spin briefly.

c. Add $10 \mu \mathrm{l} \mathrm{PCR}$ grade water to the HE Index Oligo tube (1 mM); vortex and spin briefly.

d. Add $480 \mu \mathrm{l}$ PCR grade water to the Post-LM-PCR Oligos; vortex and spin briefly.

\section{Custom blocking oligonucleotides (Tag-Capture-C)}

Resuspend the blocking oligonucleotides according to manufacturer's instructions.

\section{Multiplexing of samples}

Mix up to $1 \mu \mathrm{g}$ of each differentially indexed sample at exactly 1:1 ratios by mass to generate a multiplexed library.

2. Hybridization (3 days)

a. Heat vacuum centrifuge to $50^{\circ} \mathrm{C}$.

b. Prepare hybridization reaction for the number of pooled libraries-up to 6 libraries are captured in a single tube. For more libraries, a master mix may be made in one tube and divided into multiple tubes.

$5 \mu \mathrm{g}$ COT DNA ( $5 \mu \mathrm{l}$ of stock)/library

$1 \mathrm{nmol}$ TS-HE Universal Oligo ( $1 \mu \mathrm{l}$ of $1 \mathrm{mM}$ stock aliquot)/library

$1 \mathrm{nmol}$ of TS-HE Index Oligos ( $1 \mu \mathrm{l}$ of $1 \mathrm{mM}$ stock for each index)

up to $1 \mu \mathrm{g}$ of each uniquely indexed $3 \mathrm{C}$ library

Note: For fewer than 100,000 cells you may not recover $>1 \mu \mathrm{g}$ after indexing. Use as much as possible.

c. Vacuum centrifuge at $50{ }^{\circ} \mathrm{C}$ with tube lids open (rather than pierced) until sample is completely dry. Avoid drying for a long time after the liquid is gone.

d. For each library in the capture reaction add:

$7.5 \mu \mathrm{l} 2 \mathrm{x}$ hybridization buffer (vial 5)

$3 \mu \mathrm{l}$ hybridization component $\mathrm{A}$ (vial 6 )

e. Carefully reconstitute the DNA by pipetting and vortexing followed by briefly spinning down.

f. Replace buffers and blocking oligonucleotides in freezer prior to proceeding.

g. Preheat the Eppendorf ThermoMixer to $95^{\circ} \mathrm{C}$.

h. Preheat a PCR block to $47^{\circ} \mathrm{C}$, the lid should be heated to $57^{\circ} \mathrm{C}$.

i. Heat $4.5 \mu \mathrm{l}$ per library of pooled biotinylated oligonucleotide probes to $47^{\circ} \mathrm{C}$ in a PCR tube. Note: The capture will be at $47^{\circ} \mathrm{C}$ for $\sim 72 \mathrm{~h}$. A high-quality PCR tube is required to avoid sample loss through evaporation.

j. Denature the $3 \mathrm{C}$ library and blocking oligonucleotides by heating to $95^{\circ} \mathrm{C}$ for $10 \mathrm{~min}$.

k. After $10 \mathrm{~min}$, quickly spin the denatured library and add the entire volume to the pooled biotinylated oligonucleotides without removing from the thermocycler.

I. Mix and spin briefly before replacing in the $47^{\circ} \mathrm{C}$ PCR machine for $64-72 \mathrm{~h}$.

3. Washing and recovery of captured material (1 day)

Notes:

i. Heat reagents on an Eppendorf ThermoMixer as it is more reliable than a water bath and allows the samples to be shaken. 
ii. For capture of multiplexed libraries, scale the beads and wash buffers accordingly to the number of libraries.

iii. The Stringent Wash buffer, Wash Buffer I and Bead Wash Buffer are quite voluminous and may need to be made in multiple tubes. Split Wash Buffer I 1:2 as one third is heated.

a. Dilute the wash buffers as per table below which allows a slight excess of each.

i. Place the Stringent Wash Buffer at $47^{\circ} \mathrm{C}$ on the ThermoMixer.

ii. Place $100 \mu \mathrm{l}$ Wash Buffer I per captured library with an additional $20 \mu \mathrm{l}$ at $47^{\circ} \mathrm{C}$ on the ThermoMixer.

\begin{tabular}{|l|l|l|l|l|l|l|}
\hline & \multicolumn{3}{|l|}{ Buffer to add for 1x } & \multicolumn{3}{|l|}{ Water to add for 1x } \\
\hline $\begin{array}{l}\text { Number of libraries in } \\
\text { capture: }\end{array}$ & $\mathbf{1}$ & $\mathbf{2}$ & $\mathbf{3}$ & $\mathbf{1}$ & $\mathbf{2}$ & $\mathbf{3}$ \\
\hline $\begin{array}{l}\text { Stringent Wash Buffer } \\
\text { (vial 4) }\end{array}$ & 42 & 82 & 122 & 378 & 738 & 1,098 \\
\hline Wash Buffer I (vial 1) & 34 & 64 & 94 & 306 & 576 & 846 \\
\hline Wash Buffer II (vial 2) & 22 & 42 & 62 & 198 & 378 & 558 \\
\hline Wash Buffer III (vial 3) & 22 & 42 & 62 & 198 & 378 & 558 \\
\hline Bead Wash Buffer (vial 7) & 210 & 410 & 610 & 315 & 615 & 915 \\
\hline
\end{tabular}

Note: The streptavidin beads will likely stick to the interior of the tube. This is particularly a problem with some makes of low bind tubes. Use tubes with minimal adhesion. We use Safeseal tubes (Sorenson) for this step.

b. Prepare the streptavidin beads (M270):

i. Allow the beads to heat to RT for 30 min prior to use.

ii. Aliquot $100 \mu \mathrm{l}$ per captured library into a single $1.5 \mathrm{ml}$ Eppendorf.

iii. Place on the DynaMag and remove liquid once clear.

iv. Add $200 \mu \mathrm{l}$ of $1 \times$ Bead Wash Buffer per captured library and vortex to resuspend the beads, spin briefly.

v. Replace on the DynaMag for 5 min and remove liquid once clear.

vi. Repeat wash steps (C3b.iii-C3b.v) for a total of two washes.

vii. Resuspend the beads in their original volume (i.e., $100 \mu \mathrm{l}$ per captured library) with Bead Wash Buffer (1x) and aliquot into an appropriate number of tubes $1.5 \mathrm{ml}$ Eppendorf tubes.

viii. Place on the DynaMag, remove and discard the liquid only when ready to add the capture sample from the thermocycler. Do not allow beads to dry out.

c. Binding of biotinylated oligonucleotides:

i. Transfer the hybridization reactions to the streptavidin beads and mix thoroughly by pipetting 10 times.

ii. Spin briefly if necessary to pool all of the sample in the bottom of the tube.

iii. Place on the ThermoMixer at $47^{\circ} \mathrm{C}, 600 \mathrm{rpm}$ for $45 \mathrm{~min}$. Mix the beads with a pipette every 15 min to avoid beads settling at the bottom of the tube.

Note: Steps C3d.i-C3d.vii should be done quickly to maintain the temperature at $47^{\circ} \mathrm{C}$. 
d. Washing the streptavidin beads and bound DNA:

i. Add $100 \mu$ l of heated Wash Buffer I $\left(47^{\circ} \mathrm{C}\right)$ per captured library to the beads and bound DNA.

ii. Mix by vortexing.

iii. Place on the DynaMag, carefully discard all the supernatant when clear.

iv. Add $200 \mu \mathrm{l}$ Stringent Wash buffer per captured library heated to $47^{\circ} \mathrm{C}$ and mix.

v. Incubate for $5 \mathrm{~min}$ at $47^{\circ} \mathrm{C}$.

vi. Place the tubes on the DynaMag, carefully discard the supernatant when clear.

vii. $\quad$ Repeat stringent wash (C3d.iv-C3d.vi) for a total of 2 washes.

viii. Add $200 \mu \mathrm{l}$ Wash Buffer I (1x) at RT per captured library and mix by vortexing for $2 \mathrm{~min}$. Spin briefly to ensure no sample is lost in the lid.

ix. Place the tubes on the DynaMag, carefully discard the supernatant when clear.

X. Add $200 \mu \mathrm{l}$ Wash Buffer II (1x) per captured library and mix by vortexing for $1 \mathrm{~min}$. Spin briefly to ensure no sample is lost in the lid.

xi. Place the tubes on the DynaMag, carefully discard the supernatant when clear.

xii. Add $200 \mu \mathrm{l}$ Wash Buffer III (1x) and mix by vortexing for $30 \mathrm{sec}$. Spin briefly to ensure no sample is lost in the lid.

xiii. Place the tubes on the DynaMag, carefully discard the supernatant when clear.

xiv. Remove from the DynaMag and resuspend beads in $40 \mu \mathrm{l} \mathrm{PCR}$ grade water per capture library. Do not discard beads-DNA is not eluted but amplified off the beads.

$\mathrm{Xv}$. Store at $-20^{\circ} \mathrm{C}$ or proceed to $\mathrm{PCR}$ amplification.

SAFE STOPPING POINT: Store at $-20^{\circ} \mathrm{C}$.

4. $\mathrm{PCR}$ amplification of captured material (1 day)

a. Amplify the captured fragments in two separate reactions per captured library in a total of 14 cycles.

\begin{tabular}{|l|l|}
\hline Hybridized beads & $20 \mu \mathrm{l}$ \\
\hline KAPA HiFi HotStart ReadyMix & $25 \mu \mathrm{l}$ \\
\hline POST-LM_PCR Oligo $1 \& 2$ & $5 \mu \mathrm{l}$ \\
\hline & Total $50 \mu \mathrm{l}$ \\
\hline
\end{tabular}

\begin{tabular}{|l|l|l|}
\hline Step 1 & $98^{\circ} \mathrm{C}$ & $45 \mathrm{sec}$ \\
\hline Step 2 & $98^{\circ} \mathrm{C}$ & $15 \mathrm{sec}$ \\
\hline Step 3 & $60^{\circ} \mathrm{C}$ & $30 \mathrm{sec}$ \\
\hline Step 4 & $72^{\circ} \mathrm{C}$ & $30 \mathrm{sec}$ \\
\hline Step 5 & Go to Step 2 & $14 \mathrm{cycles}$ \\
\hline Step 6 & $72^{\circ} \mathrm{C}$ & $60 \mathrm{sec}$ \\
\hline Step 7 & $4^{\circ} \mathrm{C}$ & Hold \\
\hline
\end{tabular}

Note: Only use $20 \mu \mathrm{l}$ of DNA/Bead-using $40 \mu \mathrm{l}$ has the potential to inhibit the reaction. Two separate PCR reactions can be performed or $20 \mu \mathrm{l}$ can be stored at $-20^{\circ} \mathrm{C}$.

b. Ampure XP SPRI bead cleanup:

i. Transfer reactions to lowBind DNA $1.5 \mathrm{ml}$ microtubes. Combine up to six reactions.

ii. Add $90 \mu$ l beads per reaction, pipette 10 times to mix, allow to bind at RT for $5 \mathrm{~min}$.

iii. Place on the DynaMag, discard liquid when clear. 
iv. Add $500 \mu \mathrm{l}$ of fresh $80 \%$ ethanol without removing from the DynaMag. Avoid disturbing beads by running the ethanol down the front of the tube. Allow to sit on the rack for 30 sec at RT, then remove ethanol.

v. Remove ethanol and add another $500 \mu \mathrm{l}$ of fresh $80 \%$ ethanol, allow to sit for $30 \mathrm{sec}$ at $\mathrm{RT}$ and remove all the ethanol.

vi. Spin down in a microfuge and remove residual ethanol with a P10 pipette.

vii. Air dry at room temperature on the DynaMag until matt in appearance.

Note: Be careful not to over dry the beads as this will result in increased DNA losses.

viii. Resuspend beads in $51 \mu$ water, mix by pipetting 10 times.

ix. Incubate at RT for 2 min.

X. Recover $50 \mu$ l.

c. Assess $1 \mu \mathrm{l}$ of material using the Agilent D1000 ScreenTape system to confirm same profile as input material.

d. Quantify with Qubit BR Kit.

SAFE STOPPING POINT: Store at $-20^{\circ} \mathrm{C}$.

5. Double capture (3 days)

Note: Capture efficiency is improved by 100-1,000 fold by performing a second capture step. This increases the proportion of captured reads from 1\% to 50\%. This means only $\sim 1$ million reads are needed per viewpoint per sample and thus reduces sequencing requirements. Therefore, double capture is standard practice in our lab.

a. Pool amplified material of the parallel PCR reactions.

b. Prepare the second capture hybridization reaction using all captured material (up to $2 \mu \mathrm{g}$ ) in a single reaction. Combine:

i. $5 \mu \mathrm{g}$ COT DNA ( $5 \mu \mathrm{l}$ of stock)

ii. $\quad 1 \mathrm{nmol}$ TS-HE Universal Oligo ( $1 \mu \mathrm{l}$ of $1 \mathrm{mM}$ stock aliquot)

iii. $1 \mathrm{nmol}$ of TS-HE Index Oligos $(1 \mu \mathrm{l}$ of $1 \mathrm{mM}$ stock in total; so if you have 4 samples, use $0.25 \mu \mathrm{l}$ of each index for a total of $1 \mu \mathrm{l}$; consider making a dilution if you have many samples)

iv. Up to $2 \mu \mathrm{g}$ of amplified captured material

c. Perform hybridization, washes, and amplification as described with a 24-h hybridization at $47^{\circ} \mathrm{C}$ and treating the material as a single library.

SAFE STOPPING POINT: Store at $-20^{\circ} \mathrm{C}$.

6. Library quantification and sequencing (1 day)

a. Use qPCR with the KAPA Library Quantification Kit to calculate the concentration of adaptor containing fragments.

Make 1:10,000 and 1:20,000 dilutions of the captured material for quantification.

b. Sequence using Illumina paired-end sequencing with either 150 bp or 75 bp reads (300cycle and 150-cycle kits). 


\section{Data analysis}

The data analysis of low-input Capture-C experiments has been described (Oudelaar et al., 2017). Scripts are available in the GitHub repository (https://github.com/oudelaar/CaptureC/).

\section{Recipes}

1. Fresh lysis buffer, cool to $4{ }^{\circ} \mathrm{C}$-for 10 samples $(5 \mathrm{ml})$ :

$10 \mathrm{mM}$ Tris $\mathrm{pH} 8(50 \mu \mathrm{l} 1 \mathrm{M})$

$10 \mathrm{mM} \mathrm{NaCl}(10 \mu \mathrm{l}$ of $5 \mathrm{M})$

$0.2 \%$ Igepal CA-630 (100 $\mu$ l of $10 \%)$

1x cOmplete Protease Inhibitor Cocktail (200 $\mu \mathrm{l}$ of 25x)

$4.64 \mathrm{ml} \mathrm{PCR}$ grade water

\section{Acknowledgments}

The low-input Capture-C protocols are optimized adaptations from the Next-Generation Capture-C method (Davies et al., 2016). We thank the Wellcome Trust (Wellcome Trust Genomic Medicine and Statistics PhD Programme, reference 105281/Z/14/Z; Wellcome Trust Strategic Award, reference 106130/Z/14/Z) and the Medical Research Council (MRC Core Funding and Centenary Award reference 4050189188) for funding our work. The authors declare that there is no conflict of interest.

\section{$\underline{\text { References }}$}

1. Buenrostro, J. D., Giresi, P. G., Zaba, L. C., Chang, H. Y. and Greenleaf, W. J. (2013). Transposition of native chromatin for fast and sensitive epigenomic profiling of open chromatin, DNA-binding proteins and nucleosome position. Nat Methods 10(12): 1213-1218.

2. Davies, J. O., Oudelaar, A. M., Higgs, D. R. and Hughes, J. R. (2017). How best to identify chromosomal interactions: a comparison of approaches. Nat Meth 14: 125-134.

3. Davies, J. O., Telenius, J. M., McGowan, S. J., Roberts, N. A., Taylor, S., Higgs, D. R. and Hughes, J. R. (2016). Multiplexed analysis of chromosome conformation at vastly improved sensitivity. Nat Methods 13(1): 74-80.

4. Dekker, J., Rippe, K., Dekker, M. and Kleckner, N. (2002). Capturing chromosome conformation. Science 295(5558): 1306-1311.

5. Oudelaar, A. M., Davies, J. O. J., Downes, D. J., Higgs, D. R. and Hughes, J. R. (2017). Robust detection of chromosomal interactions from small numbers of cells using low-input Capture-C. Nucleic Acids Res 22(45): e184. 